\title{
Developing a sustainable exit strategy for COVID- I9: health, economic and public policy implications
}

\author{
Michael Anderson' (D), Martin Mckee ${ }^{2}$ (D) and Elias Mossialos' \\ 'Department of Health Policy, London School of Economics and Political Science, London WC2A 2AE, UK \\ ${ }^{2}$ Department of Health Services Research and Policy, The London School of Hygiene \& Tropical Medicine, I5-I7, London \\ WCIH 9SH, UK \\ Corresponding author: Michael Anderson. Email: M.Anderson5@lse.ac.uk
}

The rapidity with which COVID-19 spread across the world left governments with little time to respond. Now, however, as some countries see a flattening or even a decline in deaths, many are considering what a sustainable exit strategy might look like. ${ }^{1}$ Ultimately, this will require a safe and effective vaccine, coupled with new treatment for those who remain unprotected. For now, however, the emphasis has been on driving the transmission number, or R0, below 1 , so that each infected person spreads the disease to fewer than one other on average, and keeping it there with continuing restrictions on large gatherings, social distancing in everyday life and, increasingly, use of face coverings. However, it is also important that any exit strategy considers the broader health, economic and public policy implications of COVID-19.

From a health perspective, there are short- to medium-term implications. At least some of the excess deaths during the pandemic have been due to a failure to seek necessary urgent care. A large increase in weekly deaths out of hospital where COVID-19 is not listed on the death certificate is likely, in part, to be due to underdiagnosis but has occurred at the same time as substantial declines in those attending hospital with acute coronary syndrome and strokes. ${ }^{2}$ Attendances in primary care have also declined and widespread cancellations of elective surgery have delayed surgeries for patients with cancer, ${ }^{3}$ while those with coronary occlusions have also seen procedures postponed. ${ }^{4}$ Treatment algorithms have been adjusted to deliver sub-optimal treatments such as shorter durations of chemotherapy ${ }^{3}$ or thrombolysis instead of percutaneous coronary intervention..$^{5}$ As a consequence, there will be a large reservoir of unmet need, some of which will have caused conditions to deteriorate, necessitating additional or more complex treatment. ${ }^{6}$ Exit strategies must capitalise upon periods of relative suppression of COVID-19 to ensure that those affected are identified and receive care, with prioritisation given to those with highest clinical need. Mental health, so often hidden, is a particular concern as social isolation has increased loneliness, depression and anxiety. ${ }^{7}$ People with substance misuse problems have suffered, as access to addiction support services has been restricted. ${ }^{8}$ Health workers are being exposed to traumatic experiences on a daily basis, which require early support and after care to protect against long-term mental health consequences. ${ }^{9}$ Finally, action will be needed to support those who have experienced domestic violence who have struggled to access safe havens. ${ }^{10}$

From an economic perspective, there will be a need to ensure a rapid but sustainable recovery. The International Monetary Fund estimates a 6.1\% decline in gross domestic product in advanced economies in $2020,{ }^{11}$ although other analyses suggest the decline could be greater. Estimates from Germany suggest that a one-month lockdown would cost between $4.3 \%$ and $7.5 \%$ of gross domestic product ( $€ 150-260$ billion), and a three-month lockdown would cost between $10 \%$ and $20.6 \%$ of gross domestic product ( $€ 354-729$ billion). ${ }^{12}$ Some politicians are arguing that the scale of the economic harm justifies lifting restrictions earlier but this view does not withstand serious scrutiny. Few people will be willing to engage in normal activities such as eating out or attending entertainment venues if the death toll is accelerating upwards and healthcare systems, which they may need for non-COVID-19 conditions, are being overwhelmed. ${ }^{13}$ It will be important to ensure that companies, and especially the small and medium ones that are the engine of many local economies, are able to respond rapidly to the progressive lifting of restrictions. This means that governments must take 
large-scale measures to tide them over, providing interest-free loans, salary support for furloughed workers and delaying tax demands among others. ${ }^{14}$ It will also be important to put in place measures to protect them from speculators who are already seeking to undermine long-established but now vulnerable companies, especially those that have stepped up to help the struggle against COVID-19. ${ }^{15}$ Finally, as some politicians such as President Macron have noted, this pandemic is an opportunity to do things differently. The spread of infection has been facilitated in many countries by a long-term disinvestment in public services, and especially public health. There has been a realisation that the workers who are really essential to the functioning of society are those who, in the past, have been valued least. This must change.

From a public policy perspective, there are several challenges to navigate. First, countries are using technologies in novel ways to ease social distancing measures that may impinge upon civil liberties. For example, China is using an app to monitor people's movement, classifying them according to their health status and travel history. ${ }^{16}$ A similar app has been suggested in Germany. ${ }^{17}$ This raises ethical questions about the legitimate role of state intervention in restricting freedom of movement, and privacy concerns about the storage and use of data, concerns intensified by how some politicians, such as Hungary's Victor Orbán, have exploited the crisis to suspend democratic processes. ${ }^{18}$ Second, it will be important to recognise that, while the burden of premature death has fallen most on older people, it is younger people whose finances and employment opportunities will be affected disproportionately. Given that some degree of separation may continue for some time, for example designating spaces or earmarked times in shops and supermarkets for vulnerable and elderly people, it will be important to pre-empt intergenerational tensions. Third, efforts to combat COVID-19 continue to be plagued by fake news. One high-profile and damaging example has been premature claims about the effectiveness of chloroquine in treating COVID-19, leading to stockpiling and cases of chloroquine poisoning. ${ }^{19}$ France's drug-safety agency has linked chloroquine to adverse cardiac events in patients with COVID- $19,{ }^{20}$ and a trial of the drug in Brazil had to be stopped for the same reason. ${ }^{21}$ Social media companies will need to be diligent, and act appropriately even when leading figures spread misinformation. For example, Twitter and Facebook were recently quick to remove posts from Brazilian President Jair Bolsonaro, ${ }^{22}$ although Twitter declined to do the same when President Trump posted messages that were interpreted as undermining state policies on social distancing. ${ }^{23}$ Lastly, there is a tension between national and global governance. ${ }^{24}$ There is no clear mechanism to deal with a country that refuses to adopt policies to contain the spread of infection, even though its actions pose a threat to the rest of the world.

A sustainable exit strategy must be based on the epidemiology of COVID-19 but must go beyond it. It has been politically challenging to implement social distancing measures, but technically simple. In contrast, because of limited evidence, easing social distancing measures will be technically more challenging. In reality, this will be a process of trial and error. We will have to learn from each other and bear in mind that there will be challenged in translating the emerging evidence across different national contexts. We must not forget that a decade of austerity has left healthcare systems under-resourced and exposed. Future planning must include sustainable funding and building resilience to prepare for any potential major future health threats.

\section{Declarations}

Competing Interests: None declared.

Funding: None declared.

Ethics approval: Not applicable.

Guarantor: MA.

Contributorship: MA wrote and finalised the article. MM and EM revised the draft and provided critical feedback. The final version of the article was approved by all authors.

Acknowledgements: None.

Provenance: Not commissioned; editorial review

ORCID iDs: Michael Anderson (D) https://orcid.org/0000-00028454-4640

Martin Mckee (D) https://orcid.org/0000-0002-0121-9683

\section{References}

1. McKee M. A European roadmap out of the covid-19 pandemic. BMJ 2020; 369: m1556. DOI:10.1136/ bmj.m1556.

2. Spinney L. Concern as heart attack and stroke patients delay seeking help. The Guardian, 16 April 2020. See http:/www.theguardian.com/world/2020/apr/16/coronavirus-concern-heart-attack-stroke-patients-delayseeking-help (last checked 18 April 2020).

3. Burki TK. Cancer guidelines during the COVID-19 pandemic. Lancet Oncol. Epub ahead of print 2 April 2020. DOI:10.1016/S1470-2045(20)30217-5.

4. CMS. CMS Adult Elective Surgery and Procedures Recommendations: Limit All Non-essential Planned Surgeries and Procedures, Including Dental, Until Further Notice. See https://www.cms.gov/files/document/31820-cms-adult-elective-surgery-and-proceduresrecommendations.pdf (last checked 18 April 2020). 
5. Zeng $\mathbf{J}$, Huang $\mathbf{J}$ and Pan L. How to balance acute myocardial infarction and COVID-19: the protocols from Sichuan Provincial People's Hospital. Intensive Care Med. Epub ahead of print March 112020. DOI:10.1007/s00134-020-05993-9.

6. Carter P, Anderson M and Mossialos E. Health system, public health and economic implications of managing COVID-19 from a cardiovascular perspective. Eur Heart J 2020; ehaa342. DOI:10.1093/eurheartj/ehaa342.

7. Armitage R and Nellums LB. COVID-19 and the consequences of isolating the elderly. Lancet Public Health. Epub ahead of print 20 March 2020. DOI:10.1016/ S2468-2667(20)30061-X.

8. European Monitoring Centre for Drugs and Drug Addiction. EMCDDA Update on the Implications of COVID-19 for People Who Use Drugs (PWUD) and Drug Service Providers. See http://www.emcdda. europa.eu/system/files/publications/12879/emcddacovid-update-1-25.03.2020v2.pdf (last checked 18 April 2020).

9. Greenberg N, Docherty M, Gnanapragasam S and Wessely S. Managing mental health challenges faced by healthcare workers during covid-19 pandemic. BMJ 2020; 368: m1211. DOI:10.1136/bmj.m1211.

10. Taub A. A new Covid-19 crisis: domestic abuse rises worldwide. The New York Times, 6 April 2020. See https://www.nytimes.com/2020/04/06/world/coronavirus-domestic-violence.html (last checked 18 April 2020).

11. International Monetary Fund. World Economic Outlook, Chapter 1: The Great Lockdown. See https:// www.imf.org/en/Publications/WEO/Issues/2020/04/14/ weo-april-2020 (last checked 18 April 2020).

12. The German Institute for Economic Research. Making the Fight Against the Coronavirus Pandemic Sustainable. See https://www.ifo.de/en/publikationen/ 2020/monograph-authorship/making-fight-against-coronavirus-pandemic-sustainable (last checked 18 April 2020).

13. Ferguson N, Laydon D, Nedjati Gilani G, et al. Report 9: impact of non-pharmaceutical interventions (NPIs) to reduce COVID19 mortality and healthcare demand. Imperial College COVID-19 Response Team. See https://www.imperial.ac.uk/media/imperial-college/ medicine/sph/ide/gida-fellowships/Imperial-CollegeCOVID19-NPI-modelling-16-03-2020.pdf (last checked 18 April 2020).

14. McKee M and Stuckler D. If the world fails to protect the economy, COVID-19 will damage health not just now but also in the future. Nature Med 2020. DOI: 10.1038/s41591-020-0863-y.

15. Geoghegan P. As Burberry makes PPE for nurses and doctors, Brexiteer hedge funder shorts its stock. openDemocracy. See https://www.opendemocracy.net/ en/dark-money-investigations/burberry-makes-ppe- nurses-and-doctors-brexiteer-hedge-funder-shorts-itsstock/ (last checked 18 April 2020).

16. Davidson H. China's coronavirus health code apps raise concerns over privacy. The Guardian, 1 April 2020. See http://www.theguardian.com/world/2020/ apr/01/chinas-coronavirus-health-code-apps-raise-concerns-over-privacy (last checked 18 April 2020).

17. 2nd Ad-hoc-Statement: Coronavirus Pandemic Measures Relevant to Health. 2020. See https://www. leopoldina.org/uploads/tx_leopublication/2020_04 08_2ad_hoc_statement_coronavirus_en_final_01.pdf (last checked 18 April 2020).

18. Krekó P. The world must not let Viktor Orbán get away with his pandemic power-grab | Péter Krekó. The Guardian, 1 April 2020. See https://www.theguardian.com/commentisfree/2020/apr/01/viktor-orbanpandemic-power-grab-hungary (last checked 18 April 2020).

19. Beaumont P and Ratcliffe R. Chloroquine: Trump's misleading claims spark hoarding and overdoses. The Guardian, 25 March 2020. See https://www.theguardian.com/science/2020/mar/25/can-chloroquine-reallyhelp-treat-coronavirus-patients (last checked 18 April 2020).

20. National Agency for the Safety of Medicines and Health Products. Medicines Used in Patients with COVID-19: Enhanced Surveillance for Adverse Effects - Information Point. See https://www.ansm.sante.fr/Sinformer/Actualite/Medicaments-utilises-chez-lespatients-atteints-du-COVID-19-une-surveillancerenforcee-des-effets-indesirables-Point-d-information (last checked 18 April 2020).

21. Borba MGS, Val F de A, Sampaio VS, et al. Chloroquine diphosphate in two different dosages as adjunctive therapy of hospitalized patients with severe respiratory syndrome in the context of coronavirus (SARS-CoV-2) infection: preliminary safety results of a randomized, double-blinded, phase IIb clinical trial (CloroCovid-19 Study). medRxiv. EPub ahead of print 16 April 2020. DOI: 10.1101/2020.04.07.20056424.

22. Voytko L. Brazil's Bolsonaro blasted for coronavirus response, as Twitter, Facebook remove post. Forbes. 31 March 2020. See https://www.forbes.com/sites/lisettevoytko/2020/03/31/brazils-bolsonaro-blasted-for-coronavirus-response-as-twitter-facebook-remove-post/ (last checked 18 April 2020).

23. Brest M. 'Vague and unclear': Twitter rules Trump 'liberate' tweet doesn't violate coronavirus guidelines. $M S N$. See https://www.msn.com/en-us/news/politics/ vague-and-unclear-twitter-rules-trump-liberate-tweetdoesnt-violate-coronavirus-guidelines/ar-BB12OsMX (last checked 18 April 2020).

24. Anderson M, Mckee M and Mossialos E. Covid-19 exposes weaknesses in European response to outbreaks. BMJ 2020; 368: m1075. DOI:10.1136/ bmj.m1075. 